Research Square
Preprints are preliminary reports that have not undergone peer review.

They should not be considered conclusive, used to inform clinical practice, or referenced by the media as validated information.

\title{
Factors influencing depression in community-dwelling elderly patients with osteoarthritis of the knee in China: a cross-sectional study
}

\author{
Peking University \\ Xiaoyan Zheng \\ The Open University of China \\ Yaya Wang \\ The Open University of China \\ Xiaoyan Jin \\ Peking University \\ Hongjie Huang \\ Peking University Third Hospital \\ Hongbo Chen \\ Peking University \\ Yan Wang \\ The Open University of China
}

Shaomei Shang ( $\nabla$ shangshaomei@126.com )

\section{Research Article}

Keywords: Depression, Elderly, Knee osteoarthritis, Community, Influencing factors

Posted Date: February 14th, 2022

DOI: https://doi.org/10.21203/rs.3.rs-1302426/v1

License: (c) (i) This work is licensed under a Creative Commons Attribution 4.0 International License. Read Full License 


\section{Abstract}

Background: Patients with knee osteoarthritis who experience depression might have worse health outcomes. The aim of the present study was to explore the occurrence of depression and the factors influencing depression in community-dwelling elderly patients with osteoarthritis of the knee in China.

Methods: We conducted a cross-sectional, correlational descriptive study. The study included 214 participants aged 60 and older diagnosed with knee osteoarthritis.

Results: The mean total score of depression was 4.43, and depression correlated with age, body mass index (BMI), education, frequency of falls, number of comorbidities, use of walking aids, taking pain relief or cartilage protectors, pain, stiffness, physical function, social support, mobility function and the muscle strength of lower extremities ( $r=-0.342$ to 0.525 ). Analysis using hierarchical multiple regression demonstrated that falling frequency, using walking aids, the number of comorbidities, BMI, physical function, social support, and stair-climb test explained $40.8 \%$ of the variance in depression.

Conclusions: The present study demonstrated that depression among elderly people with knee OA is a serious problem. Strategies to increase patients' physical function, prevent falls, lose weight, treat comorbid conditions, and encourage them to increase positive social interaction, and engage in muscle strength training might relieve depression in these patients.

\section{Background}

Osteoarthritis $(\mathrm{OA})$ of the knee is the most common arthritic condition. ${ }^{[1]}$ Most patients will develop progressive functional limitation and physical disability with age. ${ }^{[2]}$ The prevalence of symptomatic knee OA among elderly Chinese people was reported as 10.3\% (women) and 5.7\% (men) (adjusted odds ratio (OR) 1.88). ${ }^{[3]}$ The disabling symptoms of knee OA in older patients, such as chronic pain, joint stiffness, and physical dysfunction, might cause psychological changes in patients, leading to depression. ${ }^{[4]}$ Indeed, a recent study showed that long-term OA was one of risk factors for incident depression in communitydwelling adults. ${ }^{[5]}$

In older adults, emotional distress is caused frequently by depression. ${ }^{[6]}$ It was estimated that among communities of elderly adults, significant symptoms of depression could be detected in 8 to $16 \%$ of them. ${ }^{[7]}$ Among mental disorders, depression is very common, frequently leading to a range of negative consequences, from impairments to daily life to suicide ${ }^{[8]}$ A study predicted that by 2030 , in high-income countries, the leading cause of disability will be depression. ${ }^{[9]}$ It has been acknowledged recently that among patients with $\mathrm{OA}$, anxiety, depressive symptoms, and major depression are important. ${ }^{[10]}$ Prior studies have shown that depression of individuals with OA can exacerbate pain, reduce function, and have an additive adverse impact on health-related quality of life, disability, and response to treatment. ${ }^{[11-13]}$ Even in the perioperative period of $O A$, a patient's depressive state might increase unnecessary economic burdens and suffering during the recovery period. ${ }^{[14]}$ In addition, depression can impose a significant disease burden among individuals with arthritis, their families, and society as a whole. ${ }^{[15]}$ Thus, in elderly patients with knee OA and depression, appropriate screening, assessment, and treatment is required. ${ }^{[7]}$ Unfortunately, depression among patients with $\mathrm{OA}$ is often under-recognized or under-treated in China.

Depression in community dwelling older patients is affected by a multiple of factors, including age, sex, pain, impaired mobility, low education, comorbidity, and social support. ${ }^{[16-18]}$ In addition, previous studies of elderly patients with OA of the knee have shown a significant association between depression and obesity, a longer walking time, and a slower walking speed. ${ }^{[19,20]}$ Increasing our understanding of the occurrence of depression and factors that influence it among patients with OA of the knee will help to develop nursing interventions to alleviate depression and improve these patients' quality of life. However, we know little about depression in elderly patients with OA of the knee in China. Therefore, the aim of the present study was to determine the prevalence of depression and identify the factors influencing depression among older community-dwelling patients with knee OA. We further aimed to provide clinically relevant evidence of importance of depressive symptoms in OA.

\section{Methods}

\section{The design of the study and recruitment of the study population}

This study used a cross-sectional, descriptive, correlational design. Participants were recruited from three major communities in Beijing using convenience sampling. In the three communities, elderly patients with OA of the knee were asked to join the study. The inclusion criteria were: (a) age 60 years and older and (b) diagnosed with knee OA. The exclusion criteria were: (a) under antidepressant treatment, (b) unable to take part in the tests due to symptoms of severe disability, visual impairment, or nerve dysfunction, or (c) combined with a severe disease, such as Parkinson disease, cancer, or stroke. The sample size was determined using power analysis and multiple regression with the PASS2021 software (NCSS LLC, Kaysville, UT, USA). We tested 22 predictive variables and the regression model $\left(R^{2}\right)$ was set at 0.2 to explain the amount of variation. To achieve a power of 0.8 (alpha $\left.=0.05\right)$, 91 participants (minimum) were required.

\section{Measures}

All the participants completed questionnaires, including the Short-Form Geriatric Depression Scale (GDS), the Western Ontario and McMaster Universities Osteoarthritis Index (WOMAC), and the society dimension of Short-Form Arthritis Impact Measurement Scales 2 (AIMS2), which included providing personal information. In addition, the participants performed a timed up and go test (TUG) and the stair-climb test (SCT). 
This study developed a demographic sheet to collect personal information, including age, sex, body mass index (BMI), marital status, ethnicity, residence, educational level, average monthly household income, pre-retirement occupation, medical expense, comorbidities, duration of the disease, number of diseased knees, a number of falls in the past year, use of walking aids, and consumption of pain relief or cartilage protectors.

The depression of the elderly was measured by using the Chinese version of the GDS. ${ }^{[21]}$ This scale comprises 15 self-reported measures about the patients' feelings regarding their daily lives. The only acceptable answers were 'yes' (1) or 'no' (0). ${ }^{[7]}$ 'Yes' represented a positive score for depression in 10 of the questions; whereas, 'no' represented a positive score for depression in the other five questions, e.g., 'Are you basically satisfied with your life?' 'Do you think it is wonderful to be alive now?'). The total score could range from 0 to 15 , in which more depressive symptoms were indicated by higher scores. ${ }^{[22]}$ A score ${ }^{3} 5$ defined mild depression, and a score ${ }^{3} 11$ defined moderate/severe depression. ${ }^{[19]}$ Sensitivity and specificity of the GDS have been assessed in many studies and have been proven to have good validity and reliability. ${ }^{[23-25]}$ When used in community-dwelling older adults, the Chinese eversion of the GDS had a splithalf reliability of 0.84 and a Cronbach's alpha score of $0.90 .{ }^{[26]}$

Disease extent was assessed using the WOMAC index, ${ }^{[27]}$ which comprises a questionnaire with 24 items on three subscales: physical function (17 items, score range 0-68), stiffness (two items, score range 0-8), and pain (five items, score range 0-20). Higher scores indicated increased stiffness and pain, and worse physical function. The Chinese version of WOMAC has strong internal consistency (Cronbach's alpha $=0.84-0.96$ ) and acceptable test-retest reliability, as indicated by the intraclass correlation coefficients $($ ICC $=0.76-0.85)$ for all domains. ${ }^{[28]}$ For the WOMAC index, the present study achieved a Cronbach's alpha score of 0.95 , and a split-half coefficient of 0.80 .

To measure the respondents' social support, the society dimension of AIMS2 was used. AIMS2 measures arthritis patients' quality of life using a selfassessment scale, ${ }^{[29]}$ comprising 26 items measured on a 5-point Likert scale. The society dimension contains four items, which are 'Often get together with friends or relatives', 'Often make phone calls with friends or relatives', 'Often visit friends or relatives', and 'Family or friends are willing to help me to solve problems'. The range of possible scores was $0-20$. Better family/friends social support was indicated by a higher score. An ICC of 0.90 and a Cronbach's alpha score of 0.89 supported the reliability of society dimension of the Chinese version. ${ }^{\left[{ }^{30}\right]}$ In this study, the reliability of the social support assessment had a Cronbach's alpha score of 0.77 .

The TUG test is used to determine the basic mobility skill of patients with knee OA. ${ }^{[31]}$ The TUG test comprises determining the time taken to get up from a standard chair, walk 3 m, turnaround, walk back, and sit down again. ${ }^{[32]}$ Poorer mobility was indicated by a longer TUG test time. Participants were allowed one practice trial before a timed TUG test. The TUG test was proven to have an excellent test-retest reliability and discriminant validity in community-dwelling older people. ${ }^{[33]}$ The ICC of the TUG test was 0.97 in this study.

The stair-climb test (SCT) assesses the lower extremity strength of elderly people. The SCT comprised climbing five stairs to a platform, turning around, and then climbing down. ${ }^{[34]}$ The whole test process was timed until the participant walked down the last step. Longer times indicated weaker muscle strength and poorer physical coordination. Participants were allowed one practice trial before a timed performance. The test-retest reliability and concurrent validity of SCT

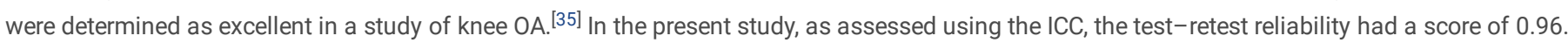

\section{Analysis of the data}

SPSS software version 23 (IBM Corp., Armonk, NY, USA) was used for all data analyses. Variables such as demographics, depression, WOMAC, social support, TUG, and SCT were assessed using descriptive statistics, i.e., the mean, standard deviation (SD), frequencies, and percentages. Among the study variables, correlations were determined using Pearson's correlation coefficient. Predictors of depression were assessed using hierarchical multiple regression analysis. All statistical tests were two-tailed and statistical significance was accepted at $p £ 0.05$.

\section{Results}

\section{Health conditions and characteristics of the participants}

Initially, this study enrolled 219 patients; however, outcome variables were missing for five patients, who were thus excluded. Therefore, 214 elderly people with knee OA were included in the final analysis. Most of the participants were female (81.8\%), married (82.7\%), and of Han ethnicity (95.8\%). Their average age was $69.2 \pm 7.63$ (standard deviation) years old, their BMI was $25.2 \pm 3.85$, and their disease duration was $5.9 \pm 7.72$ years. A high proportion of the participants (84.1\%) had at least one chronic condition, such as osteoporosis, diabetes, heart disease, or hypertension (Table 1).

Table 1

Demographic characteristics of the sample $(n=214)$ 


\begin{tabular}{|c|c|c|c|}
\hline Variable & Mean \pm SD or $n(\%)$ & Variable & Mean \pm SD or $n(\%)$ \\
\hline Age (years) & $69.19 \pm 7.63$ & Occupation before retirement & \\
\hline $60-69$ & $110(51.4)$ & Light physical & $97(45.3)$ \\
\hline 70-79 & 85 (39.7) & Hard physical & $117(54.7)$ \\
\hline${ }^{3} 80$ & $19(8.9)$ & Monthly Income (yuan) & \\
\hline Sex & & Lower than 2000 & $59(27.6)$ \\
\hline Male & $39(18.2)$ & $2000-3000$ & $55(25.7)$ \\
\hline Female & $175(81.8)$ & $3000-4000$ & $47(22.0)$ \\
\hline BMI & $25.19 \pm 3.85$ & $4000-5000$ & $23(10.7)$ \\
\hline Thin $(<18.5)$ & $11(5.1)$ & Higher than 5000 & $30(14.0)$ \\
\hline Normal (18.5-23.9) & $80(37.4)$ & Medical expense & \\
\hline Overweight (24-27.9) & $79(36.9)$ & Public expense & $41(19.1)$ \\
\hline Obese $(\geq 28)$ & $44(20.6)$ & Medical insurance & $163(76.2)$ \\
\hline Ethnic group & & At their own expense & $10(4.7)$ \\
\hline Han & $205(95.8)$ & Disease duration (years) & $5.86 \pm 7.72$ \\
\hline Others & $9(4.2)$ & $<5$ & $133(62.2)$ \\
\hline Marital status & & $5-10$ & $45(21.0)$ \\
\hline Married & 177 (82.7) & $\geq 10$ & $36(16.8)$ \\
\hline Divorced/widowed & 37 (17.3) & Number of diseased knees & \\
\hline Residence & & 1 & $94(43.9)$ \\
\hline Urban & $126(58.9)$ & 2 & $120(56.1)$ \\
\hline Rural & $88(41.1)$ & Frequency of fall in past year & \\
\hline Education & & 0 & $152(71.0)$ \\
\hline Primary school and below & $32(15.0)$ & 1 & $46(21.5)$ \\
\hline Junior high school & $68(31.8)$ & 2 or more & $16(7.5)$ \\
\hline Senior high school or equivalent & $51(23.8)$ & Using walking aids & \\
\hline College and above & $63(29.4)$ & No & $206(96.3)$ \\
\hline Number of comorbidities & & Yes & $8(3.7)$ \\
\hline 0 & $34(15.9)$ & Take pain relievers or cartilage protectors & \\
\hline 1 & $100(46.7)$ & No & $136(63.6)$ \\
\hline 2 & $38(17.8)$ & Yes & $78(36.4)$ \\
\hline 3 or more & $42(19.6)$ & & \\
\hline
\end{tabular}

The WOMAC-determined mean level of knee pain was $6.77 \pm 3.83$ (possible range $0-20$ ). Their stiffness levels were 0 to 8 (mean $=2.15 \pm 1.88$ ), their physical function scores were 0 to 68 (mean $=20.98 \pm 13.03$ ). Their level of social support was $16.79 \pm 2.95$, their mean TUG time was $13.06 \pm 3.41 \mathrm{~s}$, and their mean SCT time was $10.54 \pm 3.39 \mathrm{~s}$ (Table 2).

Table 2

Disease, Social support, TUG, and Stair-climbing of the sample $(n=214)$ 


\begin{tabular}{|llll|}
\hline Variable & Mean \pm SD or n (\%) & Variable & Mean \pm SD or n (\%) \\
\hline Pain (scores) & $6.77 \pm 3.83$ & Social support (scores) & $16.79 \pm 2.95$ \\
\hline None (0) & $4(1.9)$ & Poor $(\leq 10)$ & $7(3.3)$ \\
\hline Mild (1-7) & $121(56.5)$ & Moderate $(11-15)$ & $59(27.6)$ \\
\hline Moderate (8-14) & $80(37.4)$ & Good $(16-20)$ & $148(69.1)$ \\
\hline Severe (15-20) & $9(4.2)$ & TUG (seconds) & $13.06 \pm 3.41$ \\
\hline Stiffness (scores) & $2.15 \pm 1.88$ & $<10 \mathrm{~s}$ & $23(10.8)$ \\
\hline None (0) & $54(25.2)$ & $10-14.99 \mathrm{~s}$ & $152(71.0)$ \\
\hline Mild (1-3) & $108(50.5)$ & $15-19.99 \mathrm{~s}$ & $30(14.0)$ \\
\hline Moderate (4-6) & $50(23.4)$ & $20-24.99 \mathrm{~s}$ & $5(2.3)$ \\
\hline Severe(7-8) & $2(0.9)$ & $\geq 25 \mathrm{~s}$ & $4(1.9)$ \\
\hline Physical dysfunction (scores) & $20.98 \pm 13.03$ & SCT (seconds) & $10.54 \pm 3.39$ \\
\hline None (0) & $2(0.9)$ & $<10 \mathrm{~s}$ & $115(53.7)$ \\
\hline Mild (1-23) & $127(59.4)$ & $10-14.99 \mathrm{~s}$ & $80(37.4)$ \\
\hline Moderate (24-46) & $77(36.0)$ & $15-19.99 \mathrm{~s}$ & $14(6.6)$ \\
\hline Severe (47-68) & $8(3.7)$ & $20-24.99 \mathrm{~s}$ & $3(1.4)$ \\
\hline & & $\geq 25 \mathrm{~s}$ & $2(0.9)$ \\
\hline
\end{tabular}

TUG, timed up and go test; SCT, stair-climb test

\section{Depression}

The mean total score of the GDS was $4.43 \pm 2.89$ (range $0-15$ ). Using a score of 5 as the cutoff point, the prevalence of depression elderly communitydwelling patents with knee OA was 43.9\% (38.5\% (men) and 45.1\% (women) ( $p>0.05$ ). Among these 94 depressed patients, 85 (39.7\%) had mild depression and 9 (4.2\%) had moderate/severe depression. The three items with the highest degree of depression were "Have you dropped many of your activities and interests?" ( $n=121)$, "Do you feel you have more problems with memory than most?" ( $n=113)$, and "Do you prefer to stay at home, rather than going out and doing new things?" $(n=95)$. The three items with the lowest degree of depression were "Do you feel pretty worthless the way you are now?" ( $=20)$, "Do you often get bored?" ( $n=34)$, and "Do you feel full of energy?" $(n=38)$ (Table 3).

\section{Table 3}

Geriatric Depression Scale (GDS) scores of the sample $(n=214)$

\begin{tabular}{|c|c|c|}
\hline Items & Yes, n (\%) & No, n (\%) \\
\hline 2. Have you dropped many of your activities and interests? & $121(56.5)$ & $93(43.5)$ \\
\hline 10. Do you feel you have more problems with memory than most $\mathbb{Z}$ & $113(52.8)$ & $101(47.2)$ \\
\hline 9. Do you prefer to stay at home, rather than going out and doing new things $₫$ & $95(44.4)$ & $119(55.6)$ \\
\hline *11. Do you think it is wonderful to be alive now $₫$ & $83(38.8)$ & $131(61.2)$ \\
\hline *5. Are you in good spirits most of the time $\rrbracket$ & $80(37.4)$ & $134(62.6)$ \\
\hline *7. Do you feel happy most of the time区 & $65(30.4)$ & $149(69.6)$ \\
\hline *1. Are you basically satisfied with your life? & $60(28.0)$ & $154(72.0)$ \\
\hline 6. Are you afraid that something bad is going to happen to you $\mathbb{Z}$ & $60(28.0)$ & $154(72.0)$ \\
\hline 14. Do you feel that your situation is hopeless $\rrbracket$ & $54(25.2)$ & $160(74.8)$ \\
\hline 8. Do you often feel helpless $\rrbracket$ & $47(22.0)$ & $167(78.0)$ \\
\hline 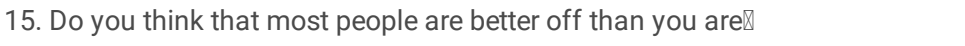 & 40 (18.7) & $174(81.3)$ \\
\hline 3. Do you feel that your life is empty? & $39(18.2)$ & $175(81.8)$ \\
\hline *13. Do you feel full of energy $\rrbracket$ & $38(17.8)$ & $176(82.2)$ \\
\hline 4. Do you often get bored? & $34(15.9)$ & $180(84.1)$ \\
\hline 12. Do you feel pretty worthless the way you are now $\rrbracket$ & $20(9.3)$ & $194(90.7)$ \\
\hline
\end{tabular}

Page 5/10 


\section{Associations between depression and other variables}

The GDS scores correlated positively with age $(r=0.264, \mathrm{P}<0.001)$ and BMI $(r=0.292, \mathrm{P}<0.001)$, but negatively with education $(r=-0.150, \mathrm{P}=0.029)$, indicating that patients who scored higher for depression were likely to be older and obese with lower educational levels. Higher GDS scores correlated with a higher frequency of falls $(r=0.305, \mathrm{P}<0.001)$, more comorbidities $(r=0.218, \mathrm{P}=0.001)$, use of walking aids $(r=0.270, \mathrm{P}<0.001)$ and taking pain relief or cartilage protectors $(r=0.169, \mathrm{P}=0.013)$. Higher GDS scores also correlated with worse pain $(r=0.419, \mathrm{P}<0.001)$, stiffness $(r=0.389, \mathrm{P}<0.001)$, and physical function $(r=0.515, \mathrm{P}<0.001)$, poorer social support $(r=-0.342, \mathrm{P}<0.001)$, lower mobility (TUG) $(r=0.391, \mathrm{P}<0.001)$, and weaker muscle strength $(\mathrm{SCT})(r=0.525, \mathrm{P}<0.001)$

\section{Factors predicting depression}

Hierarchical multiple regression analysis of GDS scores was carried out to assess the predictive abilities of demographic characteristic, scale variables (WOMAC, AIMS2), and test variables (TUG and SCT), on depression. The analysis results showed: 1), demographic variables including number of frequency of falls within the last 12 months, using walking aids, number of comorbidities, and BMI, were entered in step 1 ; 2) physical function and social support variables were entered in step 2; and 3) SCT variables were entered in step 3.

In model $1,8.9 \%$ of the variance in depression was accounted for by the frequency of falling. In model 2 , there was an increase of $4.1 \%$ in the explained variance in depression after the addition of the use of walking aids. In models 3 and 4 , respectively, the number of comorbidities increased the variance accounted for by $3.1 \%$ and BMI increased it by $2.2 \%$. In model 5, physical function increased the explained variance in depression by $15.2 \%$. In model 6 , lack of social support increased the explained variance by $1.6 \%$. In model 7 , the results of the SCT test explained $5.7 \%$ of the variance in depression. Using the full model, $40.8 \%$ of the variance in GDS scores could be accounted for (Table 4).

\section{Table 4}

Hierarchical multiple regression analysis of depression in elderly patients with knee osteoarthritis $(n=214)$

\begin{tabular}{|c|c|c|c|c|c|c|c|c|c|c|c|c|c|c|}
\hline & $\begin{array}{l}\text { Model } \\
1\end{array}$ & & $\begin{array}{l}\text { Model } \\
2\end{array}$ & & $\begin{array}{l}\text { Model } \\
3\end{array}$ & & $\begin{array}{l}\text { Model } \\
4\end{array}$ & & $\begin{array}{l}\text { Model } \\
5\end{array}$ & & $\begin{array}{l}\text { Model } \\
6\end{array}$ & & $\begin{array}{l}\text { Model } \\
7\end{array}$ & \\
\hline $\begin{array}{l}\text { Step } \\
\text { predictors }\end{array}$ & $\beta$ & $\mathrm{t}$ & $\beta$ & $\mathrm{t}$ & $\beta$ & $\mathrm{t}$ & $\beta$ & $\mathrm{t}$ & $\beta$ & $\mathrm{t}$ & $\beta$ & $\mathrm{t}$ & $\beta$ & $\mathrm{t}$ \\
\hline \multicolumn{15}{|l|}{$\begin{array}{l}1 \\
\text { Demographic } \\
\text { variables }\end{array}$} \\
\hline $\begin{array}{l}\text { Frequency of } \\
\text { falls }\end{array}$ & 1.42 & $4.67^{\star \star \star}$ & 1.22 & $4.01^{\star \star \star}$ & 1.06 & 3.51 *ᄎ & 0.93 & $3.07 * \star$ & 0.62 & $2.23^{\star}$ & 0.57 & $2.07 *$ & 0.15 & 0.55 \\
\hline $\begin{array}{l}\text { Using } \\
\text { walking aids }\end{array}$ & & & 3.29 & $3.32^{\star \star}$ & 3.48 & $3.57^{\star \star \star}$ & 3.48 & $3.62 * \star \star$ & 3.03 & 3.48 *夫 & 2.70 & $3.10^{\star \star *}$ & 1.64 & 1.90 \\
\hline $\begin{array}{l}\text { Number of } \\
\text { comorbidities }\end{array}$ & & & & & 0.55 & $2.95^{\star \star}$ & 0.51 & $2.71 * \star$ & 0.45 & $2.64 * \star$ & 0.43 & $2.56^{\star}$ & 0.37 & $2.29 *$ \\
\hline BMI & & & & & & & 0.56 & $2.61^{\star}$ & 0.33 & 1.68 & 0.32 & 1.62 & 0.20 & 1.03 \\
\hline \multicolumn{15}{|l|}{$\begin{array}{l}2 \text { Scale } \\
\text { variables }\end{array}$} \\
\hline $\begin{array}{l}\text { Physical } \\
\text { function }\end{array}$ & & & & & & & & & 2.02 & $6.98^{\star \star \star *}$ & 1.84 & $6.22^{\star \star \star}$ & 1.40 & 4.70 **> \\
\hline $\begin{array}{l}\text { Social } \\
\text { support }\end{array}$ & & & & & & & & & & & -0.77 & $-2.44^{\star}$ & -0.57 & -1.88 \\
\hline \multicolumn{15}{|l|}{$\begin{array}{l}3 \text { Test } \\
\text { variables }\end{array}$} \\
\hline SCT & & & & & & & & & & & & & 1.19 & 4.59 **> \\
\hline Adjusted $\mathrm{R}^{2}$ & 0.089 & & 0.130 & & 0.161 & & 0.183 & & 0.335 & & 0.351 & & 0.408 & \\
\hline $\begin{array}{l}\text { Adjusted } R^{2} \\
\text { change }\end{array}$ & 0.089 & & 0.041 & & 0.031 & & 0.022 & & 0.152 & & 0.016 & & 0.057 & \\
\hline
\end{tabular}

${ }^{\star} \mathrm{p}<0.05 ;{ }^{* \star} \mathrm{p}<0.01 ;{ }^{* \star} \mathrm{p}<0.001$. BMI, body mass index; SCT, stair-climb test

\section{Discussion}


Our study reported that the prevalence of depression among elderly patients with OA of the knee OA in Chinese communities was $43.9 \%$, which exceeded than that reported for older adults of a similar age in India $(23 \%),{ }^{[36]}$ the UK $(8.4 \%),{ }^{[37]}$ the US $(4.2 \%),{ }^{[38]}$ and the global median prevalence rate $(10.3 \%) .{ }^{[39]} \mathrm{A}$ systematic review suggested that depressive symptoms were a concern in approximately $20 \%$ of patients with OA. ${ }^{[10]}$ Our rate was very similar to the prevalence of $45.3 \%$ reported for older patients with knee OA in Japan, which revealing that increased knee pain might be associated with depression. ${ }^{[19]}$

The current study found that patients were more likely to be depressed because they stopped participating in many activities and interests, had problems with memory, and preferred to remain at homes. The participants' age and disease might explain this result partially. Aging memory and subsequent depression were seen more often in older people, and high levels of inflammatory disease might interact with depression to contribute to memory difficulties. ${ }^{[40]}$ In addition, activity-induced knee pain and low self-reported physical function, such as decreased lower limb strength, mobility, and balance, might stop the patients going out for activities. ${ }^{[41]}$ These results indicate that enhancing memory and professional physical activity training might improve problem solving among knee OA individuals with depression.

Correlational analyses suggested that depression among elderly patients with OA of the knee was correlated with number of comorbidities, frequency of falls, education, BMI, age, using walking aids, taking pain relief or cartilage protectors, pain, stiffness, physical function, social support, mobility, and lower extremity strength (TUG and SCT). Previous research showed that the risk of developing depression increases with age in elderly people. ${ }^{[42]}$ For the development of OA, obesity is the most modifiable risk factor. ${ }^{[20,43]}$ As the BMI values increases, joint pain symptoms and severity increase, which may cause depression. ${ }^{[44]}$

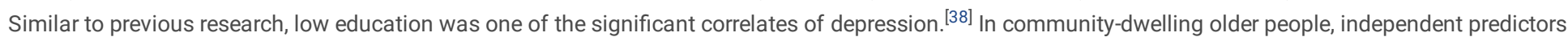
of depressive symptoms comprised frailty and poor self-rated general health. ${ }^{[45]}$ It's been reported before that everyday life can be burdensome for many elderly people because of numerous distressing ailments; therefore, patients who have more comorbidities might became more distressed. ${ }^{[42]}$ The use of walking aids, e.g. walker, crutches, and canes, can enhance a patient's support base, improve their balance, and increase activity, independence, and participation, ${ }^{[46]}$ which might improve their activity efficiency and alleviate the degree of depression in the elderly. Pain relief and cartilage protectors can ameliorate patients' pain and discomfort and protect their articular cartilage, thereby relieving depressive symptoms. ${ }^{[47]}$ Worldwide, chronic pain and depression are highly prevalent in elderly populations, with $13 \%$ of them estimated as suffering from both conditions simultaneously. ${ }^{[48]}$ Activity restriction, poorer sleep quality, and negative attitudes caused by knee pain and stiffness of patients with knee OA might exacerbate their depressive symptoms. Previous research showed a significant negative association between social support and the prevalence of depression among the elderly. ${ }^{[49]}$ Increasing social interaction might be beneficial to decrease the rate of depression among the elderly. The TUG and SCT scores indicated that mobility skill and lower extremity strength were also important correlative factors of depression. Mobility function and lower limb muscle strength training might have beneficial effects on depression of patients with knee OA.

In this study, $40.8 \%$ of the total variance in depression could be explained by the number of falls within the last 12 months, the use of walking aids, the number of comorbidities, BMI, physical function, social support, and SCT. Higher levels of depression in community-dwelling elderly patients with OA of the knee could be explained by more numerous falls, using walking aids, having more comorbidities, being overweight, having worse joint function, a low level of social support, and weak lower extremity strength. In particular, the number of falls and physical function made substantial contributions to explaining the prevalence of depression and could represent important predictors. Feelings of helplessness might result directly in a reduction in function, because subjects even found it difficult to do light housekeeping activities or go shopping. Falls in adults are a major health concern, and are the main cause of injury, hospitalization, disability, and even mortality in older adults. ${ }^{[50]}$ These serious consequences of falls may explain the higher prevalence of depression observed in fallers. Therefore, when managing depression problems, practitioners need to increase patients' physical function, prevent falls, urge them to lose weight, treat comorbid conditions, and encourage them to increase their positive social interactions and persist with muscle strength training.

\section{Limitations}

This study had some limitations. First, this study only recruited 214 elderly participants from three communities in Beijing, who may not be representative of all geriatric patients with OA of the knee in China. Second, patients with severe knee OA could not finish the tests and were thus not interviewed. These patients may suffer from more moderate to severe depression than our participants, especially among older women. Third, patients with musculoskeletal disorders other than OA were not excluded. If patients suffered from chronic musculoskeletal disorders, this might also contribute to the status of depression among this geriatric population. Future studies with more patients could further expand our knowledge in this area.

\section{Conclusion}

The present study demonstrated that depression among older patients with knee OA is a serious problem. We identified certain predictors of depression in these patients, e.g. number of falls, using walking aids, number of comorbidities, BMI, physical function, social support, and lower extremity strength, which could be dealt with inexpensively.

Given its high prevalence and profound impact on quality of life, we encourage health care providers to screen all people with knee OA for depression and emphasize its importance. In addition, enhanced efforts, comprising combining effective and safe treatments with self-management strategies, such as preventing falls, increasing positive social interactions and lower limb muscle strength training, are required for older depressed individuals with knee OA. Further appropriate interventions should be developed and evaluated for their effectiveness on depression in elderly patients with OA of the knee in China. 


\section{Abbreviations}

AIMS2: Arthritis Impact Measurement Scales 2; BMI: Body mass index; GDS: Geriatric Depression Scale; ICC: Intraclass correlation coefficients; OA: Osteoarthritis; SCT: Stair-climb test; SD: Standard deviation; TUG: Timed up and go test; WOMAC: Western Ontario and McMaster Universities Osteoarthritis Index.

\section{Declarations}

\section{Ethics approval and consent to participate}

The study protocol was approved by the Peking University Medical Ethics Committee (IRB00001052-14058). All participants provided written informed consent.

\section{Consent for publication}

Not applicable.

\section{Availability of data and materials}

The dataset supporting the conclusions of this article is included within the article (Additional file 1).

\section{Statement of STROBE guidelines}

Our study adheres to STROBE guidelines and includes a completed STROBE checklist in Additional file 2.

\section{Competing interests}

The authors declare that they have no competing interests.

\section{Funding}

Not applicable.

\section{Authors' contributions}

ZX participated in the design of the study, performed the data analysis, and drafted the manuscript. WYY and HH assessed the patients. JX, CH and WY collected and analyzed the patient data. SS was a major contributor in the design of this study and revised the manuscript. All the authors read and approved the final manuscript.

\section{Acknowledgements}

We thank all of the participants for their involvement in the study, and the research assistants for their support and help in recruitment of the participants and the data collection.

\section{Author details}

${ }^{1}$ The Open University of China, 75 Fuxing Road, Haidian District, Beijing 100039, China. ${ }^{2}$ School of Nursing, Peking University, 38 Xueyuan Road, Haidian District, Beijing 100191, China. ${ }^{3}$ Institute of Sports Medicine, Peking University Third Hospital, 49 Huayuan North Road, Haidian District, Beijing 100191 , China.

\section{References}

1. Nagai T, Tsurusaki M, Horaguchi T, Uei H, Nagaoka M. Verification of phycological factors related to health-related quality of life in elderly knee osteoarthritis: A prospective cohort study[J]. J Orthop Sci, 2019.

2. Sun X, Zhen X, Hu X, Li Y, Gu S, Gu Y, et al. Osteoarthritis in the Middle-Aged and Elderly in China: Prevalence and Influencing Factors[J]. Int J Environ Res Public Health, 2019, 16(23).

3. Tang X, Wang S, Zhan S, Niu J, Tao K, Zhang Y, et al. The Prevalence of Symptomatic Knee Osteoarthritis in China: Results From the China Health and Retirement Longitudinal Study[J]. Arthritis Rheumatol, 2016, 68(3): 648-53. 
4. Ahn H, Weaver M, Lyon D, Choi E, Fillingim RB. Depression and Pain in Asian and White Americans With Knee Osteoarthritis[J]. J Pain, 2017, 18(10): 122936.

5. Shang X, Peng W, Hill E, Szoeke C, He M, Zhang L. Incidence of Medication-Treated Depression and Anxiety Associated with Long-Term Cancer, Cardiovascular Disease, Diabetes and Osteoarthritis in Community-dwelling Women and Men[J]. EClinicalMedicine, 2019, 15: $23-32$.

6. Blazer DG. Depression in late life: review and commentary[J]. J Gerontol A Biol Sci Med Sci, 2003, 58(3): 249-65.

7. Saracino RM, Weinberger MI, Roth AJ, Hurria A, Nelson CJ. Assessing depression in a geriatric cancer population[J]. Psychooncology, 2017, 26(10): 148490.

8. Wancata J, Friedrich F. Depression: a diagnosis aptly used?[J]. Psychiatr Danub, 2011, 23(4): 406-11.

9. Ijaz S, Davies P, Williams CJ, Kessler D, Lewis G, Wiles N. Psychological therapies for treatment-resistant depression in adults[J]. Cochrane Database Syst Rev, 2018, 5: Cd010558.

10. Stubbs B, Aluko Y, Myint PK, Smith TO. Prevalence of depressive symptoms and anxiety in osteoarthritis: a systematic review and meta-analysis[J]. Age Ageing, 2016, 45(2): 228-35.

11. Arnow BA, Blasey CM, Lee J, Fireman B, Hunkeler EM, Dea R, et al. Relationships among depression, chronic pain, chronic disabling pain, and medical costs[J]. Psychiatr Serv, 2009, 60(3): 344-50.

12. Kojima M, Kojima T, Suzuki S, Takahashi N, Funahashi K, Kato D, et al. Alexithymia, depression, inflammation, and pain in patients with rheumatoid arthritis[J]. Arthritis Care Res (Hoboken), 2014, 66(5): 679-86.

13. Margaretten M, Yelin E, Imboden J, Graf J, Barton J, Katz P, et al. Predictors of depression in a multiethnic cohort of patients with rheumatoid arthritis[J]. Arthritis Rheum, 2009, 61(11): 1586-91.

14. Gong L, Chen H. Descriptive analysis of the cost-effectiveness of depressed patients undergoing total knee arthroplasty: an economic decision analysis[J]. J Orthop Sci, 2014, 19(5): 820-6.

15. Sambamoorthi U, Shah D, Zhao X. Healthcare burden of depression in adults with arthritis[J]. Expert Rev Pharmacoecon Outcomes Res, 2017, 17(1): 5365.

16. Aravena JM, Saguez R, Lera L, Moya MO, Albala C. Factors related to depressive symptoms and self-reported diagnosis of depression in communitydwelling older Chileans: a national cross-sectional analysis[J]. Int J Geriatr Psychiatry, 2020.

17. Aree-Ue S, Kongsombun U, Roopsawang I, Youngcharoen P. Path model of factors influencing health-related quality of life among older people with knee osteoarthritis[J]. Nurs Health Sci, 2019, 21(3): 345-51.

18. Lee Y, Shinkai S. Correlates of cognitive impairment and depressive symptoms among older adults in Korea and Japan[J]. Int J Geriatr Psychiatry, 2005, 20(6): 576-86.

19. lijima H, Aoyama T, Fukutani N, Isho T, Yamamoto $\mathrm{Y}$, Hiraoka $\mathrm{M}$, et al. Psychological health is associated with knee pain and physical function in patients with knee osteoarthritis: an exploratory cross-sectional study[J]. BMC Psychol, 2018, 6(1): 19.

20. Charles-Lozoya S, Cobos-Aguilar H, Tamez-Montes JC, Brizuela-Ventura JM, Rangel-Valenzuela JM, Garcia-Hernandez A. Obesity, depression and factors associated to the quality of life in total knee arthroplasty[J]. Cir Cir, 2020, 88(2): 143-49.

21. Sheikh JI, Yesavage JA. Geriatric depression scale (GDS): Recent evidence and development of a shorter version[J]. Clinical Gerontologist, 1986, 5: 16573.

22. Minami U, Nishi M, Fukaya T, Hasebe M, Nonaka K, Koike T, et al. Effects of the Change in Working Status on the Health of Older People in Japan[J]. PLoS One, 2015, 10(12): e0144069.

23. Shah A, Herbert R, Lewis S, Mahendran R, Platt J, Bhattacharyya B. Screening for depression among acutely ill geriatric inpatients with a short Geriatric Depression Scale[J]. Age Ageing, 1997, 26(3): 217-21.

24. Bae JN, Cho MJ. Development of the Korean version of the Geriatric Depression Scale and its short form among elderly psychiatric patients[J]. J Psychosom Res, 2004, 57(3): 297-305.

25. Kwak Y, Song S, Yang Y. The Relationship between Geriatric Depression Scale structure and cognitive-behavioral aspects in patients with Alzheimer's disease[J]. Dement Neurocognitive Disord, 2015, 14: 24-30.

26. Lee HCB, Chiu HFK, Kwok WY, Leung CM, Kwong PK, Chung DWS. Chinese elderly and the GDS short form: a preliminary study[J]. Clinical Gerontologist, 1993, 14: 37-42.

27. Bellamy N, Buchanan WW. A preliminary evaluation of the dimensionality and clinical importance of pain and disability in osteoarthritis of the hip and knee[J]. Clin Rheumatol, 1986, 5(2): 231-41.

28. Symonds T, Hughes B, Liao S, Ang Q, Bellamy N. Validation of the Chinese Western Ontario and McMaster Universities Osteoarthritis Index in Patients From Mainland China With Osteoarthritis of the Knee[J]. Arthritis Care Res (Hoboken), 2015, 67(11): 1553-60.

29. Guillemin F, Coste J, Pouchot J, Ghezail M, Bregeon C, Sany J. The AIMS2-SF: a short form of the Arthritis Impact Measurement Scales 2. French Quality of Life in Rheumatology Group[J]. Arthritis Rheum, 1997, 40(7): 1267-74.

30. Chu EM, Chiu KY, Wong RW, Tang WM, Lau CS. Translation and validation of Arthritis Impact Measurement Scales 2 into Chinese: CAIMS2[J]. Arthritis Rheum, 2004, 51(1): 20-7.

31. Lai Z, Lee S, Hu X, Wang L. Effect of adding whole-body vibration training to squat training on physical function and muscle strength in individuals with knee osteoarthritis[J]. J Musculoskelet Neuronal Interact, 2019, 19(3): 333-41.

32. Podsiadlo D, Richardson S. The timed "Up \& Go": a test of basic functional mobility for frail elderly persons[J]. J Am Geriatr Soc, 1991, 39 (2): 142-8. 
33. Lin MR, Hwang HF, Hu MH, Wu HD, Wang YW, Huang FC. Psychometric comparisons of the timed up and go, one-leg stand, functional reach, and Tinetti balance measures in community-dwelling older people[J]. J Am Geriatr Soc, 2004, 52(8): 1343-8.

34. Focht BC, Rejeski WJ, Ambrosius WT, Katula JA, Messier SP. Exercise, self-efficacy, and mobility performance in overweight and obese older adults with knee osteoarthritis[J]. Arthritis Rheum, 2005, 53(5): 659-65.

35. lijima H, Shimoura K, Eguchi R, Aoyama T, Takahashi M. Concurrent validity and measurement error of stair climb test in people with pre-radiographic to mild knee osteoarthritis[J]. Gait Posture, 2019, 68: 335-39.

36. Konda PR, Sharma PK, Gandhi AR, Ganguly E. Geriatric Depression and its Correlates among South Indian Urbans[J]. J Depress Anxiety, 2018, 7(4).

37. Harris T, Cook DG, Victor C, DeWilde S, Beighton C. Onset and persistence of depression in older people-results from a 2-year community follow-up study[J]. Age Ageing, 2006, 35(1): 25-32.

38. Roberts RE, Shema SJ, Kaplan GA, Strawbridge WJ. Sleep complaints and depression in an aging cohort: A prospective perspective[J]. Am J Psychiatry, 2000, 157(1): 81-8.

39. Barua A, Ghosh MK, Kar N, Basilio MA. Prevalence of depressive disorders in the elderly[J]. Ann Saudi Med, 2011, 31(6): 620-4.

40. Charlton RA, Lamar M, Zhang A, Ren X, Ajilore O, Pandey GN, et al. Associations between pro-inflammatory cytokines, learning, and memory in late-life depression and healthy aging[J]. Int J Geriatr Psychiatry, 2018, 33(1): 104-12.

41. Lin EH, Katon W, Von Korff M, Tang L, Williams JW, Jr., Kroenke K, et al. Effect of improving depression care on pain and functional outcomes among older adults with arthritis: a randomized controlled trial[J]. Jama, 2003, 290(18): 2428-9.

42. Vanltallie TB. Subsyndromal depression in the elderly: underdiagnosed and undertreated[J]. Metabolism, 2005, 54(5 Suppl 1): 39-44.

43. Ambrose NL, Keogan F, O'Callaghan JP, O'Connell PG. Obesity and disability in the symptomatic Irish knee osteoarthritis population[J]. Ir J Med Sci, 2010, 179(2): 265-8.

44. Vincent HK, Heywood K, Connelly J, Hurley RW. Weight Loss and Obesity in the Treatment and Prevention of Osteoarthritis[J]. PMR, $2012,4(5)$ : S59-67.

45. Makizako H, Shimada H, Doi T, Yoshida D, Anan Y, Tsutsumimoto K, et al. Physical frailty predicts incident depressive symptoms in elderly people: prospective findings from the Obu Study of Health Promotion for the Elderly[J]. J Am Med Dir Assoc, 2015, 16(3): 194-9.

46. Bertrand K, Raymond MH, Miller WC, Martin Ginis KA, Demers L. Walking Aids for Enabling Activity and Participation: A Systematic Review[J]. Am J Phys Med Rehabil, 2017, 96(12): 894-903.

47. Zhang W, Nuki G, Moskowitz RW, Abramson S, Altman RD, Arden NK, et al. OARSI recommendations for the management of hip and knee osteoarthritis: part III: Changes in evidence following systematic cumulative update of research published through January 2009[J]. Osteoarthritis Cartilage, 2010, 18(4): 476-99.

48. Roy R, Thomas M. A survey of chronic pain in an elderly population[J]. Can Fam Physician, 1986, 32: 513-6.

49. Chen L, Alston M, Guo W. The influence of social support on loneliness and depression among older elderly people in China: Coping styles as mediators[J]. J Community Psychol, 2019, 47(5): 1235-45.

50. Vennu V, Bindawas SM. Relationship between falls, knee osteoarthritis, and health-related quality of life: data from the Osteoarthritis Initiative study[J]. Clin Interv Aging, 2014, 9: 793-800.

\section{Supplementary Files}

This is a list of supplementary files associated with this preprint. Click to download.

- Additionalfile1.xlsx

- Additionalfile2STROBEchecklistv4crosssectional.doc 